\title{
A Review of MOOCs Implementation in Malaysian Higher Education System
}

\author{
Naemah Abdul Wahab ${ }^{1 *}$, Jamal Othman ${ }^{2}$, Rozita Kadar ${ }^{3}$, Saiful Nizam Warris ${ }^{4}$ \\ 1,2,3,4 Department of Computer and Mathematical Sciences, Universiti Teknologi MARA (UiTM) \\ Cawangan Pulau Pinang, 13500 Permatang Pauh, Pulau Pinang, Malaysia \\ Corresponding author: naema586@uitm.edu.my \\ Received Date: 16 July 2019 \\ Accepted Date: 11 November 2019
}

\begin{abstract}
Massive Open Online Courses (MOOCs) is a present technological innovation of teaching and learning in the modern higher education landscape. MOOCs have reformed the manner of instructional delivery by the educators as well as the way learners acquire their knowledge. For this reason, this study explores the definitions of MOOCs, its characteristics and advantages as well as disadvantages of MOOCs. We also emphasize on MOOCs' implementation, its issues and gaps along with its acceptance by learners and academicians especially in Malaysia. Furthermore, we look into the assessments and grading practices in MOOCs in addition to factors affecting learners' readiness to MOOCs. Lastly, we discussed some suggestion and future directions for achieving a successful MOOCs implementation in higher education settings. From all the studies done in the recent years, we can perceive that Malaysia has taken the latest step in modernizing the method of instructional delivery in higher learning institutions through the implementation of MOOCs. Although at the moment, MOOCs in Malaysia uses its own mold by blending the traditional classroom setting with only 30 percent of MOOCs used as the online instructional approach, it still encourages learners to adapt with self-directed learning and exploring various ICT tools, inspires the educators to develop updated instructional skills and provide opportunity of lifelong learning experiences to diverse learners' backgrounds. These lifelong learning practices offer open and flexible education for the entire population, either formally or informally. Recently, Malaysian MOOCs are seen progressing towards providing professional development and training courses in future that goes beyond the need of higher education and university students.
\end{abstract}

Keywords: MOOCs in Higher Education, MOOCs Implementation, MOOCs in Malaysia, MOOCs acceptance by learners

\section{INTRODUCTION}

The advancement of technology and innovation has changed the landscape of industrial operations, business management and also the education setting in our world today. In education, latest technological innovations have brought about a paradigm shift particularly in the field of higher education institutions. The extensive use of mobile devices such as smartphones and tablets in our daily task has indirectly changed the conventional classroom instructional practices to a new mode of teaching and learning process.

In order to be in line with these current technological revolutions, Massive Open Online Courses or better known as MOOCs learning has been introduced in these recent years. This new learning approach has affecting the instructors' teaching style and has reformed the manner of learners in acquiring their knowledge. According to $\mathrm{Yu}$ (2015), MOOCs are massive online education that can be accessed easily and widely on the Internet by unlimited number of students. It applies as an open education system where the learners can study any high quality courses for free of charge but some do impose a minimal fee. 
Since MOOCs uses online mode, learners are flexible to learn their interested courses without the time and place restrictions.

This novel education setting that offers the learners to learn outside the "boundaries of learning institutions" according to Nordin et al. (2015), has attracted learners from diverse backgrounds, ranging from people working in the industries, to people who work from home such as housewives and from various ages as well as from different generations. Al-Atabi and Deboer (2014) stated that early MOOCs have only focuses on teaching technical skills for engineering and computer science courses, since researchers and instructors are still in doubt of teaching critical thinking, problem solving, communication and entrepreneurship using these new method.

However, at present, MOOCs have become a new educational trending namely because of a few reasons as stated by Fesol and Salam (2016), Mansor et al. (2015) as well as Al-Atabi and Deboer (2014). MOOCs are able to cater the growing numbers of world population seeking for higher education that is no longer able to accommodate by the existing physical universities and higher education institutions. The next reason for the emergence of MOOCs is the development of broadband technology that allows Internet and information to be accessed easily and reliably has transformed the traditional approaches of teaching and learning process. MOOCs covers all the technical and non-technical courses, mostly free of charge or with a minimal cost, it is open virtually for anyone to be enrolled, thus it provide a platform for potential learners to experience a quality education at their own pace and time.

Ever since 2015, Wahid et al. (2015) mentioned about MOOCs acceptance and implementation in various universities around the world with its infrastructure has been provided and outsourced to private companies. Nevertheless, in Malaysia, MOOCs does not duplicate the established global models done in their higher institutions, but their implementation are in line with several important Malaysian National Plans as claimed by Mansor et al. (2015) in their study.

\section{MASSIVE OPEN ONLINE COURSES (MOOCs)}

MOOCs structures still maintain the same as the traditional classroom courses provided by the higher education institutions. Learners listen to lectures, learning materials are provided for reading and assessments are given to measure their understanding, learning progress and to see their performance. However, as compared to the conventional classroom settings, MOOCs teaching and learning processes are done entirely using online mode.

MOOCs are delivered via OpenLearning.com, an online learning platform based in Sydney, Australia, created by dedicated expertise with inspiringly fresh ideas to engage students with meaningful learning experiences. As stated by Al-Atabi and Deboer (2014), this platform offers learners with numerous social media features such as online forums, progress bar, karma points and badges, online team recruitments, online team project tracking or course milestone and many more.

\section{Characteristics of MOOCs}

MOOCs contain some common features. It is named as massive due to the number of participants that can join the online courses are unlimited. Other than that, it provides an open education platform for any learners to access, learn and comment on the courses they have enrolled. Most of the courses offered are free of charge; however, according to Gamage et al. (2015), some MOOCs are charging a minimal cost for issuing credentials and certification. They also added that learning materials are usually in the form of short videos, assessments such as online quizzes and peer base or self-assignments as well as discussion with instructor and peers via online forums are some of the pedagogical approaches applied in MOOCs. 
Additionally, MOOCs also hold several special characteristics. One of the characteristic mentioned in Abedi and Beikverdi (2012) study is its content. The learning materials are pre-recorded video of lectures along with interactive lecture notes and e-books. The next distinctive feature will be about the assessment datelines. MOOCs still set datelines for their assessment given; however, they have multiple datelines. Although, the learning material of MOOCs are available at all times and learners are given the flexibility to learn at their own pace and time, yet, those who wish to obtain marks are required to submit their assignments and follow the stipulated deadline. Upon scoring beyond certain threshold, certificates of accomplishments are delivered through email to the corresponding student. This is the third special characteristic of MOOCs.

Lastly, the final feature of MOOCs is its grading system. Usually, for multiple choice questions, the grading is done automatically by the system. Nevertheless in assessments that are abstract and require human grading, instructors use peer-grading or self-grading system to evaluate MOOCs participants.

\section{Advantages and Disadvantages of MOOCs}

Massive Open Online Courses brings advantages as well as disadvantages to instructors and its learners. Among the advantages of MOOCs outlined by a few earlier researches and recent studies are stimulating digital literacy, promoting global connection and open education, supporting constructive online interaction and knowledge sharing as well as inspiring universal learning and lifelong education. Conversely, MOOCs also possesses several drawbacks such as incompatibility to students who cannot learn independently, quality assurance issues, missing of humanistic and students' personalization, timeconsuming production of learning resources and integrity issue in certification. Each point will be discussed further in the next sub-topics.

\section{Advantages of MOOCs}

This new technology innovation through MOOCs to attract the new generation of learners brings many benefits and advantages. From the perspective of learners, firstly, MOOCs inspire digital literacy to its participants. According to Viswanathan (2012), learning informally through e-learning modules, online videos, webinars, podcasts, whilst participating discussion with instructors and peers via online forums or social networks will indirectly encourage a student-centred learning approach. This fits the goals of higher education reform to promote a network of individualized and independent learning as mentioned in a study by $\mathrm{Yu}$ (2015). In addition, learners all across the world get connected through the MOOCs and are not constrained by a specific instructor or course syllabus and even by a particular higher institution as mentioned by Abedi and Beikverdi (2012). They are flexible to choose their own learning time within the MOOC release cycle without any fixed curriculum timetable and they are able to view repetitively the learning materials or animated video lectures according to their own pace. All these online learning are so convenient and attracted the young generation of knowledge seekers as it can be done using their mobile devices.

Furthermore, Yu (2015) said that MOOCs support positive online interaction and knowledge sharing among the peers and instructors. Online discussion helps the learners to exchange their ideas, share their knowledge and solve their own or other people's problem. This feature provided by MOOCs platform not only widens the viewpoint of the learners, but also encourage the students to sharpen their thinking and communication skills towards a learning-based instructional method. Finally, Yu (2015) also added that MOOCs inspire universal learning and lifelong education by opening opportunities for potential learners from diverse backgrounds such as graduates seeking for additional knowledge, working people, housewives and disabled people to acquire knowledge in a flexible way at their own pace and from their own place. 
On the contrary, from the perspective of educators, MOOCs have several benefits. Yu (2015) stated in his study that MOOCs are a paradigm shift for an innovative educational transformation to increase the standard of teaching profession. Educators and higher education institutions will become more competitive and will make best effort to provide higher quality education to its prospective students. Academician will start producing high-quality learning materials, revise and reflect their instructional methods as well as improve their innovation in educational tool in order to create high-quality courses for their higher institutions. This will diminish the gap between educators and learners in adapting to the current technological changes as well as generation differences.

On top of that, although the processes of constructing high-quality teaching resources are timeconsuming, but once it is produced, educators are free from heavy repetitive explanations of their lectures, thus they can dedicate their time more on responding to students enquiries and improving their teaching methods effectively. Moreover, MOOCs teaching content can be interestingly delivered via a short animated or live action video of less than 10 minutes as well as providing additional links to other related videos for a particular topic. These new instructional tools are able to free up the constraint of teaching hours in the traditional classroom settings. Therefore, educators will have more flexible time to focus on online discussion with their students that can further enhance learners' thinking skills, self-regulated learning and creativity.

\section{Disadvantages of MOOCs}

On top of all the benefits and advantages mentioned earlier, MOOCs also possess some disadvantages or difficulties to its learners as well as the instructors. These matters are discussed in studies done by $\mathrm{Yu}$ (2015) as well as Nordin et al. (2015). MOOCs are ideal for self-directed learning; hence, it is necessary for the students especially the beginners to have a high level of independence in learning. Yet, if the students do not have a high degree of self-efficacy, then they will be not be able to complete the tasks given in MOOCs, and will be left with a mixed up feeling of disoriented and confused.

Next, according to Yu (2015), MOOCs faced with quality assurance issues. The nature of MOOCs that involves with a large-scale of learners with various learning style preferences, the lack of diversity in teaching techniques, the inadequate teaching materials, the ineffective assessment and tracking result method are some of the important factors that contribute to these issues. Subsequently, MOOCs are also lacking of active learning. In a study by Yu (2015), only a small percentage of $5 \%$ to $15 \%$ of students' enrolment have completed a course. This is due to the characteristic of MOOCs which encourage free and open learning.

The following disadvantage of MOOCs as mentioned by Yu (2015) is the missing of humanistic and students' personalization. Students will be lacking of teamwork and communication skills as a result of face to face activities absenteeism. Other than that, massive teaching approach in MOOCs has resulted in the loss of students' personalization which side-tracked from the law of education. Yu (2015) also added, another drawback of MOOCs is the time-consuming production of learning resources. This is because the instructors need to invest a lot of their time to design and produce the lecture videos, participate in online discussions and preparing the assessments. The final downside as mentioned again by $\mathrm{Yu}$ (2015) is the integrity issue in certification acknowledgment. Since there are no face to face interaction between the instructors and learners, it is hard to confirmed the learners who registered is the one taking all the assessment, getting all the credits and eligible for the certificate of recognition. 


\section{Discussion}

In summary, we make a comparison of the advantages and disadvantages of MOOCs more clearly through the table below.

Table 1 Comparison between Advantages and Disadvantages of MOOCs

\begin{tabular}{|l|l|}
\hline Advantages & Disadvantages \\
\hline Stimulating digital literacy & $\begin{array}{l}\text { Incompatibility to students who } \\
\text { cannot learn independently }\end{array}$ \\
\hline $\begin{array}{l}\text { Promoting global connection and open } \\
\text { education }\end{array}$ & Quality assurance issues \\
\hline $\begin{array}{l}\text { Supporting constructive online } \\
\text { interaction and knowledge sharing }\end{array}$ & $\begin{array}{l}\text { Missing of humanistic and students' } \\
\text { personalization }\end{array}$ \\
\hline $\begin{array}{l}\text { Inspiring universal learning and lifelong } \\
\text { education. }\end{array}$ & $\begin{array}{l}\text { Time-consuming production of } \\
\text { learning resources }\end{array}$ \\
\hline & Integrity issue in certification \\
\hline
\end{tabular}

\section{PRACTICES OF MOOCs IN MALAYSIA}

In the end of year 2014, Malaysian Ministry of Education has outlined a blueprint called "Globalised Online Learning" aimed at enhancing the quality of education and expanding education via MOOCs as stated by Mansor et al. (2015). This blueprint is expected to bring three benefits to Malaysia which is promoting high degree of international collaboration and interaction, providing global exposure and access to Malaysia's expertise in niche areas and also opening opportunities to Malaysian institutions of higher learning to showcase their best programs and best field of research worldwide.

Mansor et al. (2015) added that infrastructures and info structures are more limited in many rural areas in Malaysia which ultimately leads to urban-rural divide. However, this issue has been recognized by Malaysian Government to be fixed under the Economic Transformation Programme (ETP) for digital landscape of "Communications Content and Infrastructure".

According to Mansor et al. (2015), in 2012, Malaysian Communications and Multimedia Commission (MCMC) exposed that almost two-third of the Malaysian population are Internet users. Mansor et al. (2015) also discussed the current status of ICT in Malaysia. The ICT resources in both public and private higher education institutions are modest. The use of technology in the teaching and learning process at public higher institutions are still limited although the level of ICT skill amongst its educators and learners are good. However, there are some open universities and public universities such as Universiti Sains Malaysia (USM) and Universiti Putra Malaysia (UPM) which offer Distance-Learning (ODL) programmes are taking advantage of ICT for their delivery system as well as the administration and operation of their university.

Malaysia MOOCs is initiated in 2014 by Ministry of Education Malaysia (MOE) in collaboration with four public universities, Universiti Kebangsaan Malaysia (UKM), Universiti Putra Malaysia (UPM), Universiti Teknologi MARA (UiTM) and Universiti Malaysia Sarawak (UNIMAS) as mentioned by Nordin et al. (2015). These universities executed a pilot study on foundation courses for undergraduate students by developing four MOOCs for courses on Ethnic Relations, Asia and Islamic Civilisation, Introduction to Computer and Introduction to Entrepreneurship. These four courses were carried out using blended learning with 30 percent of the course was done via MOOCs while the remaining percentage was 
completed using any instructional method favoured by the course instructors. For all the MOOCs conducted by the respective universities, all of them have chosen OpenLearning.com platform for its implementation.

MOOCs participants are different outside and within Malaysia. In a study conducted by Mansor et al. (2015), almost half percentage of the registered learners of MOOCs outside Malaysia comes from working adults who wishes to increase knowledge for the purpose of professional development and career. Conversely, in Malaysia, most of the registered MOOCs participants are from full-time students. This might be because MOOCs approach in Malaysia aims to apply the use of online learning as a blended pedagogical in higher institutions level.

\section{MOOCs Issues and Gaps in Malaysia}

There are several concerns and gaps need to be addressed by Malaysian government and academician community in order to accomplish a successful MOOCs implementation in Malaysian higher education institutions. Some of the key directions such as identification of MOOCs participants, knowing the learners motivations, the numbers of completed participants and those who dropped the MOOCs course half-way through. All these are significant information to develop a clear and realistic Malaysian MOOCs that are relevant with national educational policies and future Malaysian higher education landscape.

\section{i) Digital divide}

The network infrastructures, Internet accessibility and ICT devices in rural and remote areas are still insufficient for the use of the underprivileged students as stated by Mansor et al. (2015). This issue need to be fixed so that the poor students are not left out in these MOOCs setting.

\section{ii) Technical Support for Instructors and Learners}

Instructors required training so that they are flexible to constantly modifying their learning resources due to the rapidly changing of technology. Mansor et al. (2015) also said that some of the traditional instructors will also need the Information Technology (IT) expert to overcome their technophobia and resistance towards this new technological innovation. For example, Sahab et al. (2018) had produced an online workshop for MOOCs developers in Universiti Teknologi MARA (UiTM) to provide a comprehensive description of online learning via MOOCs' OpenLearning.com platform and demonstrates techniques to design stimulating MOOC. They also developed a toolkit to guide MOOC developers in UiTM to create and design their MOOC content.

On the other hand, higher education should also provide learners with computer-related and technological skills to succeed in MOOCs. This is because some students from a diverse social economic backgrounds and different generation gap might be facing difficulties in accessing or adapting into the online learning component in MOOCs due to lack of IT skills and knowledge.

\section{iii) High Network Bandwidth Requirement for MOOCs Videos}

Most of the learning contents uploaded on MOOCs are animated or live lecture videos. Hence, any bandwidths limitation said Mansor et al. (2015) will affect the access speed and latency to the resources for the potential MOOCs participants. If this lackness is not catered, the learners might be demotivated to continue using MOOCs.

\section{iv) Standardization of Resources Layout and Relevance Course Structures}

Mansor et al. (2015) mentioned in their study that one of the gaps of Malaysian MOOCs is to produce a uniform learning resource and course structures to maintain its quality and relevance in meeting the requirements of public universities. Not only the materials uploaded needed a standard design, but also the courses offered should incorporated the formal higher education courses with the informal courses to 
sustain its relevancy to the potential MOOCs diverse learners. They added that the informal courses should be created for working adults to cater their educational necessities in professional training and development, interpersonal and self-improvement skills or life-long learning alongside with the Malaysian National Blueprint objective.

\section{v) Constructing Malaysian Local MOOCs Platform}

Malaysia should have its own MOOCs platform and each Malaysian Public Universities (MPU) must hold the responsibility and have the capability to maintain it as recommended by Azhan et al. (2016). This is because the current MOOCs platforms in many MPU are not integrated to each other and we have to follow the terms, conditions and restriction of copyright stipulated by that platform. By developing a home-grown Malaysian MOOCs platform, MOOCs in all MPU can be connected with each other to easily provide standardize learning resources and course structures with a more secure environment. Besides, learners will have more flexibility in choosing and enrolling in any listed courses offered by any Malaysian higher institutions.

\section{vi) Absence of Proper Verification and Accreditation for MOOCs Leaners}

Having our own Malaysian MOOCs platform not only for the purpose of standardization, collaboration and interaction, nevertheless, Mansor et al. (2015) cited that it is to facilitate in verification and accreditation processes of a MOOCs participant. By having a standard platform, it would be easier for all Malaysian higher institutions that involve in MOOCs to create and accept the same authentication and certification system formed. In a study by Azhan et al. (2016), they recommended using local university identification and password for authentication purposes in line with the university policy. Furthermore, he also suggested using a learners' performance dashboard system to monitor student's activities, involvement and assessments that can help the instructors in grading and issuing certification of completion.

\section{MOOCs in Malaysian Universities}

Malaysia has realized that in line with the latest technological changes in education, higher education should also make a paradigm shift to traditional methods of teaching and learning. Therefore MOOC has been introduced as a new education innovation in the country's higher education landscape. According to Al-Atabi and Deboer (2014) as well as Mansor et al. (2015), Taylor's University was the first Malaysian higher education institution offering entrepreneurship mini courses as MOOCs in 2013. These mini courses aim to act as pilot study for full university programmes which may be implemented in the future.

Mansor et al. (2015) added that in 2014, five more higher education institutions embarked into MOOCs which consist of four public universities and a private institution. They are Universiti Putra Malaysia (UPM), Universiti Kebangsaan Malaysia (UKM), Universiti Teknologi MARA (UiTM), Universiti Malaysia Sarawak (UNIMAS) and Open University Malaysia (OUM). It is also said that Malaysia in 2014, is the only country that implemented MOOCs at a national scale. These six higher education institutions that started on MOOCs are using a platform based in Sydney, Australia known as OpenLearning.com.

Although Mansor et al. (2015) said that MOOCs globally aim to provide a solution in addressing the need for more universities and to cater the learners' growth in developing countries including countries in Asia; however, Malaysia implemented MOOCs for different reasons. Firstly, MOOCs in Malaysia are directed at supplementing traditional learning and teaching processes at higher education levels to the latest webbased technology to meet the needs of the current generation. Next, we are aware that MOOC in Malaysia is still new and are likely to progress in the coming years, there have been initiative by private higher education institution such as Taylor's University and Open University Malaysia (OUM) to broaden their scope of MOOCs to not only offering academic courses, but as mentioned by Mansor et al. (2015), they 
also develop MOOCs for informal courses as part of lifelong learning initiative such as Visual and Culinary Arts courses. Finally, MOOC courses in Malaysia hopefully facilitate the general public to explore and try out a new means of obtaining flexible education formally or informal.

\section{MOOCs Acceptance among Malaysian Academicians and its Current Practices}

According to a survey done by Mansor et al. (2015) in their study, among 120 respondents comprising academics in Malaysia, 92\% of them believed that the current learning models in higher educational setting are necessary to be changed to meet the present technological advancement and learners need. The study also added the academician strongly agreed that technology and educational innovation are indispensable as a compulsory tool for learning purposes in this modern era. Nevertheless, about half of the instructors feel that MOOCs should not substitute the existing traditional classroom teaching but it will co-exist with the old instructional methods. Malaysia initiative to MOOCs in higher education is still exploratory and is still restricted due to the inadequate infrastructure and access to connect the urban-rural digital divide.

At present, six universities in Malaysia comprising of four public universities that are Universiti Kebangsaan Malaysia (UKM), Universiti Putra Malaysia (UPM), Universiti Teknologi MARA (UiTM) and Universiti Malaysia Sarawak (UNIMAS), as well as two private higher institutions which are Taylor's University and OUM have conducted MOOCs as mentioned by Nordin et al. (2015) as well as Mansor et al. (2016). These four public universities executed a pilot study on compulsory courses for undergraduate students that are courses on Ethnic Relations, Asia and Islamic Civilisation, Introduction to Computer and Introduction to Entrepreneurship. On the other hand, Taylor's University offers entrepreneurship mini courses and informal interests such as visual and culinary arts as MOOCs while Open University Malaysia work together with Apple in providing their MOOCs via iTunes $U$ that are available for iPad and iPhone users.

At the start, only 30 percent of the whole course was implemented using MOOCs hosted by an Australian online learning platform called OpenLearning.com. Mansor et al. (2015) as well as Azhan et al. (2016) said that this learning platform provides a space for educators to deliver teaching and learning resources through video lectures, pdfs, and PowerPoint slides as well as assessments activities to students. Contrarily, Mansor et al. (2015) mentioned that in Open University Malaysia (OUM), they chose iTunes $\mathrm{U}$ as their MOOCs platform which offers a similar package as OpenLearning.com, but limited to iPhone and iPad users only. Therefore, instructors create podcast, provides an education segment via OUM's internet radio called iRadio and produce audio books for their visually impaired students as the learning materials. However, all these learning contents in OUM must be developed in compatible Apple devices formats.

All the learning resources and online assessments for the MOOCs learners are developed in-house. Nevertheless, according to Mansor et al. (2015), tertiary institutions involved in the production of materials for MOOC in practice require expert and technical assistance from the university in the field of graphic, multimedia and instructional designing, lecture content developer and language editors.

Azhan et al. (2016) added that by 2020, the Malaysian government aspires to run $15 \%$ of all courses in Malaysian Public Universities (MPU) into MOOC courses and wishes to offer a minimum of three MOOCs each year from every MPU. 


\section{ASSESSMENT PRACTICES AND PEER GRADING OF MOOCS}

Azhan et al. (2016) said that the MOOCs learners can register and enrol multiple of times in each courses without any validation process required. The students follow the online lectures, watch the videos uploaded, read the course materials provided and join the online discussion with their instructors or peers. Every process is almost the same with the traditional classroom environment as stated by Ardis and Henderson (2012) except that $30 \%$ of the teaching and learning process is done online. Students still need to go through course assessments to get the certificate of course completion. As for MOOCs assessments, instructors can evaluate students in various online assessment methods through virtual discussions, forums, online quizzes, automated assessments and peer-reviewed assignments.

Some of the evaluation such as online quizzes and multiple choice questions (MCQ) can be machinegraded automatically. However, for certain assignment, Noguchi and Fujimura (2015) mentioned that they need to be either peer-grading according to the solution rubric prepared by the course instructor, otherwise marked by the course instructor itself or other subject matter experts as stated by Reeves (2013). Noguchi and Fujimura (2015) in their paper explained how the online peer grading system in MOOCs works. This evaluating system consists of five processes as illustrated by Figure 1 and explained in Table 2.

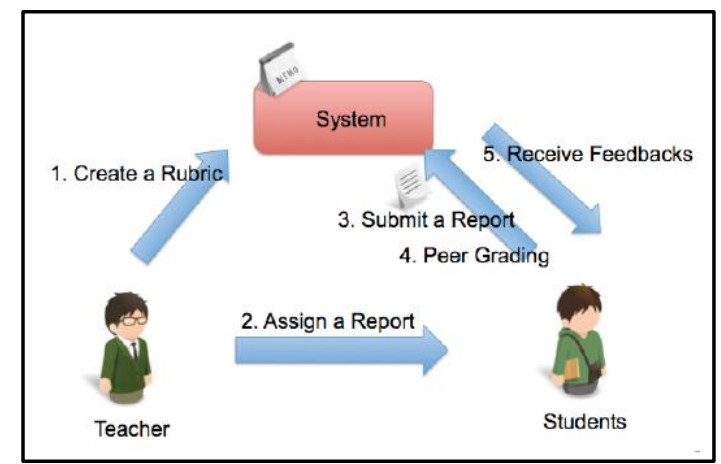

Figure 1: Peer Grading System Overview by Noguchi and Fujimura (2015)

Table 2: Processes involve in Peer Grading System by Noguchi and Fujimura (2015)

\begin{tabular}{|l|l|l|}
\hline No & Process & Description \\
\hline 1 & Create a Rubric (Teachers) & $\begin{array}{l}\text { Teachers will upload into the system the contents of an } \\
\text { assignment. They will also attach together a solution rubric } \\
\text { of the given assignment for peers' reference in grading. }\end{array}$ \\
\hline 2 & Assign a Report (Teachers) & $\begin{array}{l}\text { In the physical classroom lesson, the teachers will brief the } \\
\text { assignment content, the solution rubric which will be used as } \\
\text { a guide for grading and the submission dateline. }\end{array}$ \\
\hline 3 & Submit a Report (Students) & $\begin{array}{l}\text { Assignment reports should be uploaded in accordance of } \\
\text { the dateline. Students are allowed to amend their report } \\
\text { multiple times as long as not exceeding the dateline } \\
\text { stipulated. Once done, students may grade their own report } \\
\text { (self-grading) according to the answer rubric, however this } \\
\text { action is optional. }\end{array}$ \\
\hline 4 & Peer Grading (Students) & $\begin{array}{l}\text { After assignment report submission, peers are given certain } \\
\text { period of time (e.g. a week) to grade by following the } \\
\text { solution rubric. }\end{array}$ \\
\hline 5 & Receive Feedback (Students) & $\begin{array}{l}\text { Students can view the comment and grade given by their } \\
\text { peers. Peers responses can be used as references and } \\
\text { guidance for improvement of their future assignment reports. }\end{array}$ \\
\hline
\end{tabular}


At this stage, it is still too early to include any effective assessment methods, quality assurance practices or accreditation process for the implementation of Malaysian MOOCs in those six institutions mentioned earlier. However, since the MOOC courses implemented in all of these institutions is a compulsory course, the assessment component is an important obligation to be measured. As stated by Mansor et al. (2015), at present, Taylor's University offer a certificate of completion for students who completed a full MOOC course while Open University Malaysia is still considering for the best method for evaluating and granting accreditation certificates to its learners.

\section{FACTORS OF MOOCs ACCEPTANCE AMONGST LEARNERS}

Previously, we have discussed about MOOCs implementation in Malaysian universities as well as the academic's acceptance. Now, we will explore into MOOCs from the view point of the learners. There are six key factors that need to be considered towards learners' acceptance and readiness to MOOCs as mentioned by Ayub et al. (2017) as well as Fesol and Salam (2016). Firstly, MOOCs facilitate the learning flexibility through self-regulated learning environment. The MOOCs environment will indirectly create independent learners that are able to acquire knowledge without any time limit or any geographical barriers. The flexibility of time, location and the advantages of learning according to our own study pace is the most appealing factors of MOOCs to its learners especially those learners who are occupied with work and family commitment. Besides that, MOOCs is also convenient for slow learners. The online videos, learning materials and recorded lectures can be seen repeatedly by the learners at their own time to fit in their tight schedule, thus it is very helpful and meaningful way of acquiring the knowledge needed. Students can also communicate online and offline with their instructors or peers via convenient and fast manner. If only the lecturers are able to motivate their student to be self-directed and selfdiscipline in their learning, MOOCs will be one of the best and useful mediums to create outstanding human capital for today's higher education system.

Participation and interaction in online learning will be the next factor emphasized by Ayub et al. (2017) as well as Fesol and Salam (2016) in their studies. MOOCs can be a good medium to share ideas, to discuss virtually with peers or instructors, to engage in group collaborative learning and to support interactivity with learners from different backgrounds. Some shy students will prefer online medium to express their ideas easily and comfortably, while some learners needed more time to explore, read and think before writing their comments or providing solution for questions discussed in their real class due to their tight schedule. Therefore, we can sum up that group discussion, online interaction and collaborative learning conveyed through MOOCs is a meaningful way of learning process.

Subsequently, technology constraints play an important role in the success of MOOCs and its student acceptance. Some of the technical problem such as low bandwidth, slow internet speed and software compatibility or device-dependant issues must be addressed so that learners can access MOOCs contents conveniently. Unreliable internet connection and device-dependant learning contents will cause the learners to lose their interest in MOOCs and will increase higher percentage of dropouts for this kind of courses. Since many of the younger generation learners use mobile devices in their daily life, plus most of the materials uploaded on MOOCs consist of videos and audios format, hence any technologically hindrance should be avoided.

User-friendly design of learning material is another significant aspect towards learners' acceptance to MOOCs. According to Ayub et al. (2017), they listed a few criteria to be considered in producing high quality learning contents in MOOCs. The learning resource interfaces should be simple and clear. All the modules should be well-structured by chapters and weekly subtopics. The MOOCs contents should use simple but appealing presentation layout and clear navigation buttons. All the functions and links 
provided on the learning materials should not be confusing. As for the information placed on the lecture videos, it should come from good reading materials, precise, easily comprehend, highlighted with important details and elaborated clearly if required for learners' understanding. However, the videos should not be lengthy, preferably within 3 to 15 minute duration per video. The quality and caption of the videos should also be considered.

Ayub et al. (2017) also suggested OpenLearning.com to adopt Facebook format in its platform so that students can comment in the learning modules. Other than that, they also advised OpenLearning to enable all learning videos on MOOCs to be on automated preview mode by streamlining all browsers. In terms of assessments, hands on activities and exercises should be given weekly or at the end of each lesson. Learners also feel that reflection activity at the end of each lesson is a good way to test their understanding. Nevertheless, a few improvements on the assessment should be done, such as the instructions and solution rubrics given should be precise and clear. As for the multiple choice questions, instant response on the choosen answer and a brief explanation after the learners have answered the question is better so that they can learn from their mistakes immediately. All in all, the learning resources, tasks and assessments should accommodate the diverse backgrounds of MOOCs learners.

Ayub et al. (2017) also added that the technical guidance is also a crucial factor to be catered to facilitate the MOOCs learners. The higher institutions involved with MOOCs will need to provide learners with computer-related and technological skills to succeed in MOOCs. We are aware that MOOCs students come from different social economic backgrounds. Moreover, some learners are matured older generation of workers or housewives that might be facing difficulties in adapting into the MOOCs online learning components due to lack of IT skills and knowledge. For that reason, higher education needs to make learners digitally literate by providing technical assistance in MOOCs contents and components.

The final factor highlighted by Fesol and Salam (2016) is the dependency on classroom teaching. It is undeniable that traditional classroom setting has long been creating a meaningful and comfortable faceto-face interaction between students and instructors. At this stage, the students feel that online learning has not been able to entirely substitute traditional learning methods. It can be observed that students who are not confident to become independent learners or have negative attitude towards online learning will be less prepared to accept MOOCs. On the other hand, students who prefer technology, who are up to face new challenges and have high level of self-independence will be ready to attempt MOOCs. Fesol and Salam (2016) said that the interactive contents and stimulating online activities such as lecture videos, tutorial videos, online quizzes and virtual group discussion are able to solve this anxiety and uncertainty.

Nevertheless, whatever the perception of a student on MOOCs, it is important to understand their readiness and acceptance to MOOCs since they are the users of this technology. If these factors are not properly catered, MOOCs will be another ineffective innovation which will only be used momentarily in the higher education system. According to a recent paper by Yang et al. (2017), system quality, course quality and service quality are three most important credentials of the continuance intention of MOOCs participants. They proposed a research model to investigate the quality factors that support the acceptance and continuation motivation for MOOCs participants as seen in Figure 2. 


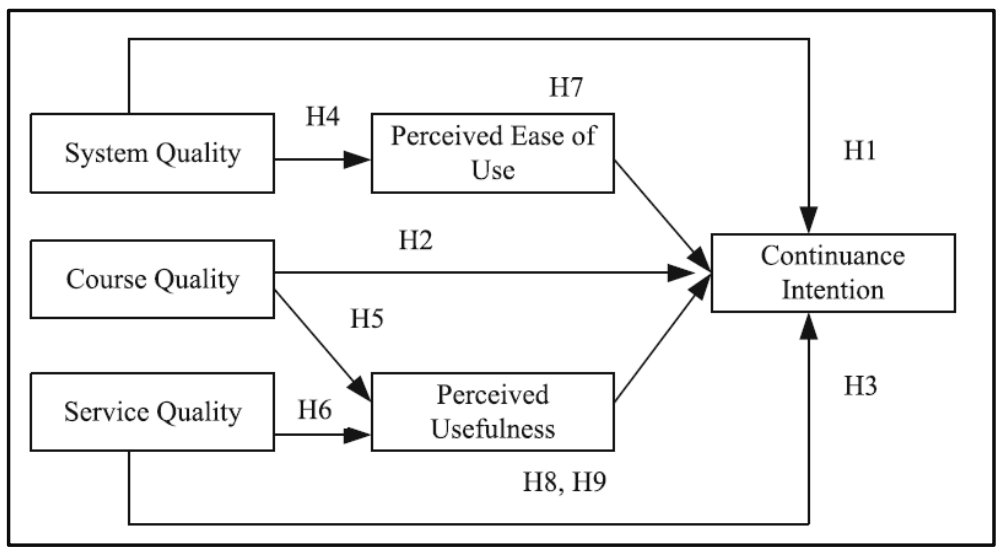

Figure 2: Research model by Yang et al. (2017)

From their study, they come up with three core recommendations. It is unquestionable that human interaction plays a crucial role in providing a high quality service, thus, MOOCs developers are advised to try their very best to cater in personalization of learners' diverse learning styles. In terms of maintaining the course quality, Yang et al. (2017) suggested comprehensive, clear and related course information and course materials of a MOOC course. They advised using graphical illustration for further understanding wherever appropriate. Finally, developing suitable system functionalities for both instructors and learners used are important features for preserving good system quality. This factor should be taken care of by MOOCs platform operators.

\section{FUTURE DIRECTIONS AND CONCLUSION}

Massive Open Online Courses (MOOCs) offer a flexible online educational system for diverse learners' qualification and backgrounds by providing them more freedom in terms of learning time, self-paced study and place. With the availability of Internet connection, MOOCs learners are able to register as a participant of an online course, access and watch all the MOOCs lecture videos multiple times, try all the activities provided, complete all the assessment given and discuss with peers as well as their instructors virtually.

In this paper, we have discussed the fundamental concept of MOOCs, its benefits and shortcomings as well as issues and gaps that need to be addressed. We also explained about MOOC implementation in Malaysian universities and also perceived the acceptance of MOOCs amongst learners and the academicians. We also gathered many significant suggestions and future directions from studies as early as 2012 until the recent research done in 2018 in producing more effective MOOCs.

Rather than comparing MOOCs with the traditional mode of instructions in higher learning environment, an earlier study done by Reeves (2013) suggested the researchers to concentrate on making online, blended and traditional classroom learning works harmoniously through a solid educational framework. As MOOCs progresses during the years, in a study by Nordin et al. (2015), they foresee the importance of accessing the learning style of MOOCs participants and their adaptive feedbacks. They recommended these two significant items to be measured and implemented at three stages which are pre-mooc, during mooc and post-mooc. The finding of these researches can be very useful in personalizing suitable learning materials and tasks for individual learners according to their learning preferences. Hence, the higher education institutions through the teaching instructors are able to offer an engaging learning experience through effective online learning medium and developing motivated independent learners. Once educators manage to tailor their teaching materials and learning resources in line with their students learning styles, 
Fesol and Salam (2016) proposed the researchers to analyse the acceptance and readiness of learners towards MOOCs implementation and also measure MOOCs effectiveness. The suggested studies are essential criteria in implementing successful MOOCs at higher education institutions.

At present, MOOCs is still at an early stage and is evolving rapidly in positive directions. Although MOOCs in Malaysia is not replacing the traditional classroom teaching instead complementing the existing pedagogical methods, Malaysian higher education institutions need to identify methods to maintain the success of MOOCs, to preserve the quality aspects of the course and to produce effective teaching, learning and certification practices. It is hope that MOOCs will play a significant role in providing lifelong learning experiences in an open context to diverse potential learners in a very convenient and flexible manner.

\section{REFERENCES}

Abedi, M., \& Beikverdi, A. (2012). Rise of massive open online courses. Paper presented at the 4th International Congress on Engineering Education - Improving Engineering Education: Towards Sustainable Development, Penang. pp. 84-87.

Al-Atabi, M., \& Deboer, J. (2014). Teaching entrepreneurship using Massive Open Online Course (MOOC). Technovation, 34(4), 261-264. doi: 10.1016/j.technovation.2014.01.006

Ardis, M. A., \& Henderson, P. B. (2012). Software engineering education (SEEd): Is software engineering ready for MOOCs? ACM SIGSOFT Software Engineering Notes, 37(5), 14-14. doi: $10.1145 / 2347696.2347720$

Ayub, E., Wei, G.W., \& Yue, W.S. (2017). Exploring Factors Affecting Learners' Acceptance of MOOCs Based on Kirkpatrick's Model. Paper presented at the 8th International Conference on E-Education, E-Business, E-Management and E-Learning, New York, NY, USA. pp. 34-9.

Azhan, M. H. B. N., Saman, M. Y. B. M., \& Man, M. B. (2016, March 22-23). A Framework for Collaborative Multi-Institution MOOC Environment. Paper presented at the International Conference on Internet of things and Cloud Computing, Cambridge, United Kingdom.

Dahlan, A.R.A., Juhari, S.S., \& Shafiee, A.S.A. (2015). MOOCs at International Islamic University Malaysia. International Journal of Computer Science and Information Technology Research, 3(2), 140-149

Fesol, S.F.A., \& Salam, S. (2016). Towards MOOC for Technical Courses: A Blended Learning Empirical Analysis. International Journal on Advanced Science, Engineering and Information Technology, 6(6), 116-121.

Gamage, D., Fernando, S. \& Perera, I. (2015, August 24-26). Quality of MOOCs: a review of literature on effectiveness and quality aspects. Paper presented at the 8th International Conference on UbiMedia Computing (UMEDIA), Colombo. pp. 224-229.

Mansor, F., Latifah, A. L., \& Amina, M. (2015). MOOCs in Malaysia: A preliminary case study. Paper presented at the E-ASEM Forum: Renewing The Lifelong Learning Agenda for The Future, Bali, Indonesia. 
Noguchi, S., \& Fujimura, N. (2015). Implementation and Experience of the Online Peer Grading System for Our Real Class. Paper presented at the 2015 ACM Annual Conference on SIGUCCS (SIGUCCS '15), New York, NY, USA. pp. 125-128. doi: http://dx.doi.org/10.1145/2815546.2815581

Nordin, N., Norman, H., \& Embi, M. (2015). Technology acceptance of massive open online courses in Malaysia. Malaysian Journal of Distance Education, 17(2), 1-16.

Reeves, T. (2013). Thoughts on The Quality of Learning in MOOCs. Paper presented at the IADIS International Conference e-Learning, Prague.

Sahab, S.S., Embi, R., Luaran, J., Hussin, A.A., Dahlan, J., Hamdan, M.A.I., Ikram, M.S.M., Hasshim, M.S., Nazeri, N.H.M., \& Mazlan, M.A. (2018, September 12-13). Let's Mooc; Toolkit for Mooc Development. Paper presented at the The International University Carnival on e-Learning (IUCEL), International Islamic University Malaysia, Gombak, Malaysia.

Viswanathan, R. (2012). Teaching and Learning through MOOC. Frontiers of Language and Teaching, 3, $32-40$.

Wahid, R., Mat, B., Sani, M.A.M., \& Subhan, M. (2015). Sharing Works and Copyright Issues in Massive Open Online Courseware (MOOC). International Journal for Research in Emerging Science and Technology, 2(10), 24-29.

Yang, M., Shao, Z., Liu, Q., \& Liu, C. (2017). Understanding the quality factors that influence the continuance intention of students toward participation in MOOCs. Educational Technology Research and Development, 65(5), 1195-1214.

$\mathrm{Yu}, \mathrm{C}$. (2015). Challenges and changes of MOOC to traditional classroom teaching mode. Canadian Social Science, 11(1), 135-139. doi: 10.3968/6023 